\title{
A pertinência da noção de ambiências urbanas para o tema dos direitos dos idosos: perspectivas brasileiras
}

\author{
The relevance of the notion of urban ambiences to the theme of the rights of the elderly: Brazilian \\ perspectives
}

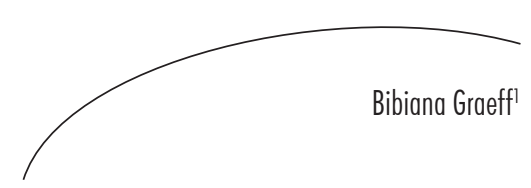

\section{Resumo}

No Brasil, o reconhecimento das funções sociais da cidade e do dever de amparo aos idosos foi um dos avanços da Constituição Federal de 1988 (artigos 182 e 230). Em um contexto de urbanização e de envelhecimento populacional, um Estatuto da Cidade e um Estatuto do Idoso foram também adotados pelo legislador brasileiro. O presente trabalho, baseado em pesquisa exploratória de natureza qualitativa, teve por objetivo investigar se a noção de ambiência urbana vem sendo empregada ou se mostra pertinente para a análise e a efetivação dos direitos do idoso no Brasil. Foram feitas buscas nas bases de dados IusData e periódicos CAPES e LILACS, com os termos "ambiência" e "idoso" e seus respectivos plurais nos títulos e resumos, período livre até fevereiro de 2014, encontrando-se apenas um resultado, na área da Enfermagem. Além das principais leis federais relacionadas às cidades e aos idosos, e de leis orgânicas municipais (São Paulo, Rio de Janeiro e Porto Alegre), a pesquisa também se apoiou em referencial teórico nas áreas da Gerontologia, do Direito e da Arquitetura e Urbanismo. A ideia de ambiência, que se refere a um ambiente experimentado, situando a experiência do sujeito no centro da reflexão, revela-se oportuna para se pensar na cidade enquanto espaço que reflita a heterogeneidade da velhice e que propicie um envelhecimento ativo e digno. Ainda que essa noção apareça apenas timidamente em algumas leis urbanísticas municipais, não sendo legalmente definida ou habitualmente empregada pelos juristas, as ambiências urbanas são intimamente relacionadas com o Direito, já que são, ao mesmo tempo, determinadas pelo Direito (entre outros fatores) e determinantes para a efetivação de direitos.

\section{Abstract}

In Brazil, the recognition of the city's social functions as well as the duty of supporting the elderly was one of the innovations introduced by the 1988 Federal Constitution (articles 182 and 230). A City's Act (2001) and an Elderly People's Act were also introduced in the Brazilian legal system, within an urbanization and aging population context. Based on a qualitative and explorative research, this article seeks to investigate

Palavras-chave:

Envelhecimento. Ambiências Urbanas. Direitos do Idoso. Cidades. Brasil.

Curso de Gerontologia, Escola de Artes, Ciências e Humanidades. Universidade de São Paulo. São Paulo, SP, Brasil. 
if the notion of "urban ambience" has been employed or could be relevant for the analysis and implementation of elderly rights in Brazil. Searches were made in the databases IusData, Periodicals CAPES and LILACS in the fields of titles and abstracts with the terms "ambience(s)" and "elderly(s)" until February, 2014, in which only one result was found, in the area of Nursing. The research was also based on the main federal Laws related to cities and elderly as well as municipal Laws (São Paulo, Rio de Janeiro and Porto Alegre) and references in Gerontology, Law, Architecture and Urbanism. The idea of ambience, which refers to an environment experienced by someone, places people's experiences at the heart of the thought process. This concept seems appropriate to think about the city as a place that reflects the heterogeneity of the elderly and promotes active and dignified aging. Although this concept is still rarely used in Brazilian legal acts, with no legal definition and unknown to lawyers, urban ambiences are, in fact, closely related to the law, since they are determined by Law (among other factors) and are determinant for enforcing rights.
Key words: Aging. Urban Ambiences. Elderly Rights. Cities. Brazil.

\section{INTRODUÇÃO}

Ainsi, l'homme bumanise la terre, il la marque de son empreinte physique et la couvre de signes qui la font parler un langage pour lui intelligible.

François Ost

Aquele que garante o bem-estar dos outros garante o seu próprio.

Provérbio chinês

Com a Constituição da República Federativa do Brasil de 1988, ${ }^{1}$ estabeleceram-se bases normativas sólidas para o desenvolvimento de uma política urbana voltada à promoção das funções sociais da cidade e do bem-estar de seus habitantes (artigos 182 e 183). O mesmo texto consagrara também, de modo pioneiro, direitos específicos aos idosos (art. 230), tema abordado por Ramos, Faleiros \& Graeff. ${ }^{1-4}$ Ambas as lutas - aquela pela qual se almeja uma cidade socialmente justa, e aquela pela qual se busca o reconhecimento do idoso enquanto sujeito de direitos - são movimentos ${ }^{5}$ que afloram num mesmo momento histórico e político no Brasil: as duas últimas décadas do século XX, período pós-Ditadura Militar. São causas distintas, mas inter-relacionadas, pois não há cidade que garanta o bem-estar de seus habitantes se for o palco de descaso em relação aos direitos fundamentais, inclusive aqueles de grupos minoritários, como o dos idosos. ${ }^{6,7}$

Segundo a lei brasileira, "idosos" são as pessoas com idade igual ou superior a 60 anos, na concepção do Direito brasileiro (Lei $\mathrm{n}^{\circ}$ $8.842 / 1993$, art. $2^{\circ}$; Lei ${ }^{\circ} 10.741 / 2003$, art. $\left.1^{\circ}\right),{ }^{8,9}$ embora alguns pesquisadores, como Camarano, ${ }^{10}$ já questionem este marco etário, sugerindo uma revisão e aumento da idade para 65 anos.

Após a conquista na seara constitucional, houve mais alguns anos de esforços para que se alcançassem, em ambos os domínios, importantes avanços legislativos. Dentre estes, cabe destacar o Estatuto da Cidade, adotado em $2001,{ }^{11}$ e o Estatuto do Idoso, ${ }^{9}$ de 2003.

Parece haver, no Brasil, poucos estudos jurídicos dedicados a pensar a cidade enquanto espaço de promoção e efetivação dos direitos dos idosos, ${ }^{12}$ embora em outras áreas do conhecimento, pesquisas voltadas às relações entre o espaço urbano e a velhice ou o envelhecimento estejam aflorando em diversos países, notadamente a partir da difusão do programa "Cidade Amiga do Idoso”, da Organização Mundial da Saúde (OMS), que se deu, por exemplo, amplamente no Canadá e na França. ${ }^{13}$ Aliás, em janeiro de 2012, durante o colóquio Droit de Vieillir, na cidade de Dijon, 
França, lançou-se a "Rede francófona de cidades amigas do idoso" (Réseau francophone des villes amies des aînés), reagrupando cidades de diversos países francófonos; já em setembro de 2013, na $2^{\text {a }}$ Conferência Internacional de Cidades Amigas do Idoso, na cidade do Quebeque, Canadá, foi lançada a Rede Iberoamericana de Cidades Amigas do Idoso (RICA). A experiência do programa em Portugal é relatada por Centeio et al. ${ }^{14}$

Apoiada no conceito de envelhecimento ativo, difundido em 2002, também pela OMS, ${ }^{15}$ como sendo "um processo de vida moldado por vários fatores que, isoladamente ou em conjunto, favorecem a saúde, a participação e a segurança de idosos", a iniciativa visa a estimular as cidades para que "se tornem mais amigas dos idosos". ${ }^{16}$ Ipsis literis, uma tal cidade seria "aquela que estimula o envelhecimento ativo ao otimizar oportunidades para saúde, participação e segurança, para aumentar a qualidade de vida, à medida que as pessoas envelhecem". ${ }^{16}$

O programa "Cidade Amiga do Idoso" teve origem em uma pesquisa com grupos focais de idosos, cuidadores e prestadores de serviços de 33 cidades de todas as regiões do mundo. Com essa enquete, estruturada em oito aspectos da vida urbana - 1) espaços abertos e prédios; 2) transportes; 3) moradia; 4) participação social; 5) respeito e inclusão social; 6) participação cívica e emprego; 7) comunicação e informação; 8) apoio comunitário e serviços de saúde -, chegou-se a uma lista de fatores urbanos que seriam amigáveis aos idosos. O Brasil esteve à frente nesta ação, por meio dos trabalhos de Alexandre Kalache; o Rio de Janeiro, em especial o bairro de Copacabana, constou como uma das cidades pioneiras desse programa, segundo pesquisa conduzida por Laura Machado. A iniciativa tenciona que outras cidades possam aplicar a mesma metodologia de investigação, por meio de grupos focais locais, a fim de se tornarem "amigas dos idosos".

Se, por um lado, a noção de "envelhecimento ativo" ainda não aparece em leis federais, por outro, já integra um decreto presidencial, ${ }^{17}$ um decreto do Estado de São Paulo, ${ }^{18}$ ou ainda a legislação da cidade de São Paulo (Lei Municipal $\mathrm{n}^{\circ}$ 14.905, de 6 de fevereiro de 2009, que instituiu a "política municipal de envelhecimento ativo"). ${ }^{19}$ Com base nesse dispositivo municipal, diversos distritos de São Paulo deram início a ações de implantação de "bairros amigos do idoso", como as iniciativas da Vila Clementino (com pesquisadores da UNIFESP), da Mooca e do Brás.

No distrito da Mooca organizaram-se, em 2011 e 2012: audiências públicas; um trabalho de conscientização sobre os cuidados com calçadas e sobre a necessidade de atendimento especial nas praças de atendimento; uma distribuição de panfleto sobre prevenção de quedas; e um curso sobre cuidadores de idosos. Também foram implementadas reuniões com grupos focais em parceria com equipe de docentes do curso de graduação em Gerontologia da Escola de Artes, Ciências e Humanidades (EACH), da Universidade de São Paulo. ${ }^{19,20}$

Além dos municípios, outros equipamentos ou entes federados (como o Estado do Rio Grande do Sul ${ }^{21}$ e, mais recentemente, o Estado de São Paulo ${ }^{18,22}$ ) lançaram-se em iniciativas "amigas do idoso", sempre ancorados no conceito de envelhecimento ativo. Assim, este conceito já tem sido aplicado em políticas urbanas brasileiras, conquanto o Estatuto da Cidade ${ }^{11}$ não tenha feito nenhuma referência específica ao "envelhecimento".

Outra noção bastante em voga para se pensar o espaço urbano, e que ainda não integra o vocabulário dos juristas, embora já desponte timidamente na legislação urbanística municipal brasileira, é a noção de ambiência. Com efeito, uma busca de artigos na base da Faculdade de Direito da USP "Iusdata" com os termos "ambiência" e "ambiências" em todos os campos de busca até janeiro de 2014 apresentou apenas dois resultados. ${ }^{23,24}$ Preliminar e genericamente, pode-se afirmar, seguindo-se Thibaud, ${ }^{25}$ que "a ambiência se apresenta como um espaço-tempo experimentado, em termos de sensibilidade". Pensar-se em ambiência, por vezes também designada pelo termo "atmosfera", significa situar a experiência do sujeito/grupo com relação ao espaço no centro da reflexão. 
$\mathrm{Na}$ medida em que os espaços urbanos devem ser adequados e favoráveis ao bem-estar e à efetivação dos direitos dos idosos, questionase se a noção de ambiência poderia contribuir na formulação de políticas públicas brasileiras que avancem nesse sentido. Subsidiariamente, interroga-se se tal noção é ou poderia ser reconhecida e/ou acolhida pelo Direito brasileiro.

Para o enfrentamento dessas questões, considerou-se necessário um estudo sistêmico de diversos textos normativos (em especial, o Estatuto da Cidade, ${ }^{11}$ o Estatuto do Idoso 9 e alguns planos diretores em que se pôde observar o emprego do termo "ambiência"). O presente trabalho parte, pois, de uma perspectiva jurídica, o que não o isenta de um indispensável apoio em bibliografias nacionais e/ou estrangeiras das áreas gerontológica e urbanística. Considerase, deste modo, que este estudo está dotado de roupagem multidisciplinar.

O referencial teórico que serviu como ponto de partida para a formulação do objetivo da presente pesquisa foi o conceito de ambiência, tal como formulado por Tixier, ${ }^{26}$ Thibaud $^{25}$ e tal como trabalhado em sua relação com o envelhecimento humano. ${ }^{27} \mathrm{~A}$ partir desse embasamento, e de referencial teórico levantado em pesquisa anterior relacionada ao programa "Cidade Amiga do Idoso", foram feitas pesquisas e análises com interpretação sistemática da legislação brasileira em diversos níveis (federal, estadual e municipal). A pesquisa legislativa voltou-se às principais leis federais relacionadas às cidades e aos idosos, bem como a leis estaduais (São Paulo) e municipais (São Paulo, Porto Alegre e Rio de Janeiro). A escolha das localidades foi determinada pelo referencial relacionado às políticas "Cidade Amiga do Idoso" e pelos resultados da revisão bibliográfica.

Além das buscas restritas ao IusData, já mencionadas, foram feitas buscas nas bases de dados IusData, periódicos CAPES e LILACS com os termos "ambiência" e "idoso" e seus respectivos plurais nos títulos e resumos, até janeiro de 2014, encontrandose apenas um resultado, que se relaciona à área da Enfermagem. ${ }^{27}$ Como procedimentos complementares para a exploração do conceito de ambiência em suas diferentes acepções, empreendeu-se pesquisa livre, não exaustiva, com esse termo na jurisprudência do Tribunal Superior do Trabalho, bem como no Diretório de grupos de pesquisa do CNPq (buscas eletrônicas realizadas em agosto de 2011).

Os dados foram tratados pela análise documental e os resultados estruturados para a elaboração do artigo por meio do método do plan français, estruturação de trabalhos escritos ou orais comumente empregada na cultura jurídica francesa. Por este método, a apresentação do trabalho se divide geralmente em duas partes, inter-relacionadas por uma lógica de complementaridade ou de oposição. Assim, a própria estruturação do artigo reflete a essência e a lógica da discussão empreendida. Neste trabalho, primeiramente, tentar-se-á apresentar os contornos da noção de ambiência e sua possível juridicidade, para que se possa, num segundo momento, discorrer sobre a importância das ambiências urbanas enquanto fator a ser considerado para a promoção dos direitos da pessoa idosa no Brasil.

\section{Os contornos da noção de ambiência urbana:} uma juridicidade possível?

Discutida há mais de 15 anos por arquitetos e urbanistas, a noção de ambiência perpassa diversas áreas do conhecimento, como a Saúde, ${ }^{28}$ a proteção laboral ${ }^{*}$, as Ciências

\footnotetext{
* Neste âmbito, o termo aparece, em diversas decisões trabalhistas, adquirindo o sentido de ambiente/espaço, como "ambiência de trabalho" ou "ambiência laboral", geralmente em casos envolvendo acidentes de trabalho ou adicional de insalubridade. V.g. Decisões do Tribunal Superior do Trabalho: Processo RR - 11120072.2008.5.09.0093 Data de Julgamento: 01/06/2011, Relator Ministro: Aloysio Corrêa da Veiga, $6^{a}$ Turma, Data de Publicação: DEJT 05/08/2011; AIRR - 237-08.2010.5.20.0000 Data de Julgamento: 23/03/2011, Relator Ministro: Luiz Philippe Vieira de Mello Filho, $1^{\text {a }}$ Turma, Data de Publicação: DEJT 01/04/2011; AIRR - 213-77.2010.5.20.0000 Data de Julgamento: 06/10/2010, Relator Ministro: Guilherme Augusto Caputo Bastos, $2^{\mathrm{a}}$ Turma, Data de Publicação: DEJT 15/10/2010.
} 
Agrárias $^{* *}$ ou a Gerontologia. ${ }^{27} \mathrm{Na}$ área da Saúde, a política do HumanizaSUS ${ }^{29}$ adota a "ambiência" para o sistema de saúde único no Brasil com base em três eixos: a) a confortabilidade de trabalhadores e usuários, com a valorização de elementos do ambiente que interagem com as pessoas; b) a concepção de espaços de encontro, de reflexão e de participação que permitam o próprio repensar da organização espacial; e c) a arquitetura como ferramenta facilitadora de mudança do processo de trabalho.

Como observa Tixier, ${ }^{26}$ na França, em meados da década de 1970, a noção era identificada com a criação nas escolas de arquitetura de uma disciplina ancorada na técnica e nas ciências voltada ao "controle das ambiências" (acústica, iluminação, condições térmicas); mais tarde, no início da década de 1990, surgiram uma unidade de pesquisa e um mestrado em "Ambiências arquiteturais e urbanas", junto ao laboratório CERMA na Escola Nacional Superior de Arquitetura de Nantes, criado por J. P. Peneau, e ao laboratório CRESSON, na Escola Nacional Superior de Arquitetura de Grénoble, criado por J. F. Augoyard e por J. J. Delétré.

$\mathrm{Na}$ interface da Arquitetura com a Gerontologia, o termo já foi, por exemplo, associado à acepção de "espaço construído como fator de envelhecimento saudável". ${ }^{27} \mathrm{Na}$ perspectiva urbanística, a noção já é bastante difundida globalmente, e os campos de pesquisa voltados ao assunto adquirem particularismos regionais: enquanto no Brasil, as dimensões

\footnotetext{
** Uma linha de pesquisa denominada "construções rurais e ambiência", que volta-se a "estudar e desenvolver técnicas construtivas e sistemas de climatização em projetos de sistemas de suporte a vida animal, dentro dos conceitos de conforto ambiental, segurança e ética, no âmbito das construções rurais, principalmente aplicadas à bovinocultura, suinocultura e avicultura industriais; inclusive estudar e avaliar as condições poluentes do ambiente interno (poeira, ruídos e gases) em sistemas de produção comercial de animais domésticos". Grupo de pesquisa "Ambiência animal e zootecnia de precisão", da Unicamp, cadastrado no CNPq. Disponível em: <http://dgp.cnpq.br/buscaoperacional/ detalhelinha.jsp?grupo $=0079503$ JCEEKEF\&seqlinha $=3>$. Acesso em: 29 ago. 2011.
}

antropológica e política são bastante presentes, na Alemanha, destacam-se as determinantes geográfica e estética, e na América do Norte, os aspectos ambiental e projetual. ${ }^{25}$

Embora a noção de ambiência circule em diversas disciplinas, sendo, aliás, intrinsecamente interdisciplinar, a reflexão que se pretende promover neste trabalho parte de um enfoque urbanístico para, num segundo momento, situarse numa perspectiva jurídica.

Ambiências urbanas: enfoque urbanístico

Os urbanistas tendem a considerar que a noção de ambiência já não se restringe à sua dimensão original, muito relacionada ao conforto, sendo hoje os aspectos socioculturais elementos indispensáveis em sua apreciação. Há, contudo, dificuldades em se definir tal noção, tida como abrangente, motivo pelo qual não há a pretensão de se empreender aqui uma exposição exaustiva, mas apenas de se pincelar algumas visões encontradas.

Tixier $^{26}$ faz uma boa síntese de elementos que permitem melhor compreensão da noção de ambiência:

- a mesma implica uma relação sensível ao mundo;

- estudá-la necessita uma abordagem multidisciplinar, voltando-se a atenção às dimensões construídas, sensíveis e sociais do espaço;

- ela não se refere a uma escala espacial particular (habitação, espaços públicos, espaço de trabalho, espaços de mobilidade ou ainda de representação); é uma noção "trans-escalar", que se aplica tanto a espaços ordinários quanto a espaços mais cenografados;

- ela situa a experiência do usuário no coração do projeto, sendo utilizada tanto para o estudo dos espaços, quanto para sua concepção. 
Pelo fato de a ambiência não denotar o espaço em si, mas as inter-relações entre o espaço e a experiência sensível, parece necessário pensar sempre em ambiências, no plural. De fato, um espaço não pode ser associado a uma única ambiência, não somente porque a ambiência de um lugar varia segundo a hora, as condições meteorológicas, a ocupação, entre outros fatores, mas igualmente porque um mesmo espaçotempo pode representar distintas ambiências, para sensibilidades diversas.

Um recinto animado pelo gênero musical Modinha poderá ser estimulante para uns, e enfadonho para outros. Todavia, embora se reconheça que uma ambiência apresente variações, "ela geralmente apresenta características que lhe conferem uma identidade, que nos permitem reconhecê-la". ${ }^{26}$ Uma ambiência é composta por elementos objetivos, concretos (ex: um espaço com área verde, um espaço com determinado cheiro), e por elementos subjetivos (ex: um espaço que proporcione bem-estar, um espaço facilitador de encontros e de discussões). Os elementos objetivos serão fisicamente mensuráveis (o cheiro é este, a cor é esta, a temperatura é esta), mas a apreciação, a sensação e a vivência subjetiva sobre os mesmos serão suscetíveis de variação, dependendo dos atores sensíveis envolvidos (o cheiro é ruim, o cheiro é bom; a cor é feia, a cor é bela; está muito frio, não está tão frio).

$\mathrm{O}$ adjetivo "urbano", proveniente do latim urbs, que significa "cidade", vem delimitar a noção de ambiência. ${ }^{30}$ Portanto, ao se tratar de ambiência urbana se estará tratando da ambiência da cidade, o que remete notadamente à ideia de coletividade, de espaços públicos, de equipamentos e serviços públicos, de convivência e experiência compartilhada.

\section{Ambiências urbanas: enfoque jurídico}

$\mathrm{Na}$ legislação brasileira, percebe-se que, ao lado das expressões "meio ambiente", "ambiente natural", "ambiente construído" ou ainda "paisagem", a noção de "ambiência" vem sendo (ainda timidamente) introduzida, especialmente quando se trata de ambiência urbana, ou de patrimônio histórico e cultural. Com efeito, em função dos resultados obtidos nas buscas bibliográficas e legislativas, parece ser bastante raro, na legislação urbanística brasileira, o emprego do termo "ambiência"; e quando este termo aparece, vem desacompanhado de qualquer definição. Assim, o Plano Diretor do Rio de Janeiro ${ }^{32}$ elege, na qualidade de princípio da política urbana, a "garantia de qualidade da ambiência urbana como resultado do processo de planejamento e de ordenação do território municipal" (art. 2, IX, grifos nossos). Em vários outros artigos, a lei se refere à ambiência urbana (art. 14; art. 160, VII; art. 183, XVI; art. 314, §2, IV), à ambiência de bens tombados (art. 134), à ambiência das Áreas de Proteção do Ambiente Cultural (art. 135) sem, contudo, apresentar qualquer definição. $\mathrm{O}$ legislador local parece, no entanto, ter distinguido "ambiência" de "ambiente", na medida em que se refere ao "ambiente natural da ambiência urbana" (art. 14, IX).

No Plano Diretor de Porto Alegre, ${ }^{33}$ as "ambiências" são referidas enquanto componente do Patrimônio Cultural (art. 14), também sem nenhuma precisão quanto ao significado da expressão. Em 2010, ${ }^{34}$ acrescenta-se naleium novo tipo de Área Especial de Interesse Ambiental: as "Áreas de Ambiência Cultural", que se somam às "Áreas de Proteção do Ambiente Natural" e às "Áreas de Interesse Cultural". Distinguindose destas últimas, que são áreas "que apresentam ocorrência de Patrimônio Cultural" (art. 92), as "Áreas de Ambiência Cultural" são aquelas que "por apresentarem peculiaridades ambientais e culturais, devem ser preservadas, podendo também constituir transição entre as Áreas de Interesse Cultural e os demais setores da Cidade" (art. 92-A).

Interessante notar que, na identificação de tais áreas, consideram-se "as relações físicas e culturais com o entorno" (mesmo artigo, $\$ 1^{\circ}$ ), o que remete ao aspecto relacional, uma das características da noção de ambiência, tal como considerada pelos urbanistas. Mas, se a noção de ambiência parece 
ainda não ser juridicamente definida no Brasil, há que se confrontá-la com uma noção vizinha, esta sim, definida pela lei, e bem conhecida pelos juristas: a noção de meio ambiente.

O meio ambiente é definido pela legislação brasileira como "o conjunto de condições, leis, influências e interações de ordem física, química e biológica, que permite, abriga e rege a vida em todas as suas formas" (Lei no 6.938, de 31 de agosto de 1981, que instituiu a Política Nacional do Meio Ambiente, art. $3^{\circ}$, I). ${ }^{35}$ Veja-se que este conceito se aproxima da noção urbanística de ambiência em seu aspecto dinâmico de interações e influências, porém acaba sendo reduzido a uma perspectiva de ciências naturais, enquanto se limita às dimensões física, química e biológica.

A noção de ambiência é, portanto, mais ampla do que a de meio ambiente, tal como definido pela Lei que estabelece a Política Nacional do Meio Ambiente no Brasil, ${ }^{35}$ por englobar influências e interações de ordem histórica, cultural, social e psicológica. Ressalta-se que a análise restringese à definição acolhida pela lei que estabelece a política nacional do meio ambiente no Brasil, pois existem outras fontes que associam outros fatores à noção de meio ambiente.

A própria doutrina atenta para outras definições possíveis. Nesse sentido, Michel Prieur $^{36}$ observa que existem dois sentidos habituais para a palavra environnement, que não faz objeto de uma definição geral pela lei francesa. Um sentido lhe é conferido pelas ciências da natureza, que o enquadram como um conjunto de dados e de equilíbrios de forças concorrentes que condicionam a vida de um grupo biológico; o outro sentido comum é, segundo o autor, cunhado por arquitetos e urbanistas, e serve a qualificar a zona de contato entre um espaço construído e o ambiente (natural ou artificial).

Segundo Bestetti, ${ }^{27}$ o termo "meio ambiente" pode ser sinônimo de ambiência, desde que compreendido também como meio moral, e não apenas material. Contudo, de um ponto de vista jus-filosófico, parece que uma diferença sutil persiste, pois se o conceito de meio ambiente é suscetível de um revestimento ecocêntrico (como por exemplo, aquele posto pela deep ecology), o conceito de ambiência parece pensado e aplicado a partir de uma ótica predominante, se não exclusivamente antropocêntrica: pensase no espaço físico com a finalidade precípua da "humanização", do "conforto", do "bem-estar".

Os trabalhos e pesquisas com foco na ambiência até podem admitir que os equilíbrios naturais sejam levados em conta como um componente a ser preservado, dependendo do escopo, do espaço e da cultura em que a ambiência é pensada, mas a preservação de tais equilíbrios não será tanto uma finalidade "em si", mas representará mais uma escolha em função daquilo que interessa, em última análise, ao ser humano. Aliás, quando a ambiência é o cerne de estudos agrários, por exemplo, a finalidade dos mesmos será, muitas vezes, de natureza utilitária, visando, em última instância, à satisfação das necessidades (e valores) do ser humano, portanto ainda que as questões bioéticas sejam consideradas.

Apesar dessa constatação sobre a natureza antropocêntrica das considerações em termos de ambiência, trabalhos embasados na ambiência devem hoje, mais do que nunca, ancorar-se num paradigma ecológico: "repensar a ambiência urbana é refletir sobre a qualidade de vida na cidade perante as atuais condições de crise global e local de maneira diferente à dos anos 1990"; "a mudança na biosfera com o aquecimento global e suas consequências catastróficas faz com que nos rendamos à evidência e reconheçamos o componente natural como base para a construção do território, necessário para o encontro entre o projeto natural e o artificial". ${ }^{31}$

Assim, de um ponto de vista do direito positivo brasileiro, a noção de ambiência parece poder conviver com a noção de meio ambiente, possuindo nuances diferenciadoras. Ainda que a noção de ambiência urbana não seja definida pela lei, ou habitualmente apreendida pelos juristas, pode-se, sem dúvida, afirmar que as 
ambiências possuem também um substrato jurídico, porquanto são condicionadas, entre outros fatores, pelo Direito.

Com efeito, as normas jurídicas e sua aplicação exercem influência sobre o ambiente e, consequentemente, sobre as ambiências, por meio, por exemplo, da limitação de volume sonoro, das permissões de construir, do zoneamento, da proteção da paisagem, da proteção do patrimônio histórico-cultural e da própria educação e promoção da diversidade e das manifestações minoritárias. Na configuração das ambiências urbanas, há também, por óbvio, o que pode escapar do Direito (i.e. condições meteorológicas, herança genética, que pode ser um dos determinantes de sensibilidades e capacidades individuais), e o que vai contra a lei (i.e. crimes, violação de direitos fundamentais).

Mas se, por um lado, o Direito, enquanto construção sociocultural é fator de influência na formação das ambiências, sendo igualmente uma das variáveis socioculturais que influem sobre o processo de envelhecimento humano, por outro, também as ambiências são determinantes para a efetivação de direitos, como será demonstrado a seguir.

\section{Ambiências urbanas: uma noção pertinente para se pensar os direitos dos cidadãos idosos?}

Ainda na esteira do parágrafo anterior e a título de introdução ao presente tópico, cabe uma reflexão preliminar: por que "ambiência urbana", em vez de "ambiente urbano" enquanto espaço de realização dos direitos dos idosos? Sem dúvida, seria possível a opção pelo termo "ambiente urbano" para, com base no mesmo, desenvolver-se uma reflexão sobre os direitos do cidadão idoso. Contudo, quanto mais o Direito se impregna de conceitos jurídicos indeterminados subjetivados, tais como a "beleza" (questões estéticas), o "bem-estar", "diversões" ou a própria "felicidade" ***, fazendo com que, portanto, a percepção do sujeito se torne também relevante, mais a noção de ambiência, que envolve não somente a aferição de elementos objetivos, mas igualmente a consideração de elementos subjetivos, parece pertinente ao universo jurídico.

Também é preciso, de pronto, destacar que o conceito de ambiências urbanas não se revela pertinente somente para se pensar nos direitos dos idosos, mas para se pensar nos direitos de qualquer cidadão, independentemente da idade. Contudo, pelo fato de os idosos constituírem uma minoria, ${ }^{37}$ que vem encontrando diversas dificuldades de inclusão nos espaços urbanos, como demonstram de modo geral as pesquisas relacionadas aos métodos do "Cidade Amiga do Idoso" (como veremos a seguir), esse grupo parece particularmente afetado e interessado por essa relação entre as ambiências urbanas e a efetivação de direitos. Como já mencionado em outro trabalho, as minorias "podem ser identificadas por distintos fatores, como os que distinguem minorias étnicas, linguísticas, religiosas, ou territoriais, por exemplo. A ideia de minoria é, por vezes, associada a um grupo que simplesmente queira conservar sua especificidade no interior de uma coletividade numericamente mais expressiva. Mas essa definição não aponta

\footnotetext{
*** $\mathrm{Na}$ Constituição Brasileira de $1988^{1}$ veja-se a noção de "paisagens naturais notáveis", Art. 23, III e bens de "valor estético", Art 24 VII; "bem-estar" dos cidadãos na cidade, Art. 182 e "bem-estar" dos idosos (Art. 230). Quanto ao termo “diversões”, o Estatuto do Idoso prevê que: "o direito à liberdade compreende, entre outros, os seguintes aspectos: (...) IV - prática de esportes e de diversões" ( $\int 1^{\circ}$, IV, do artigo $10^{\circ}$, grifos nosso). Veja-se também o projeto de emenda constitucional que atualmente tramita no Congresso nacional, e que institui um direito à "busca da felicidade" individual e coletiva (PEC n 19/2010). Em diversos países, a felicidade já foi positivada enquanto direito fundamental (Constituições do Butão, art. 20, do Japão, art. 13, e da Coreia do Sul, art. 10). Em julho de 2011, a própria ONU adotou uma resolução pela qual reconhece a felicidade como "um objetivo humano fundamental", convidando todos os Estados membros a elaborarem "novas medidas que reflitam melhor a importância deste objetivo em suas políticas públicas”. Ademais, na busca de outros parâmetros de desenvolvimento, alguns têm defendido a proposta do índice de Felicidade Interna Bruta (FIB), em substituição ao Produto Interno Bruto (PIB).
} 
para a situação de inferiorização social, política ou econômica vivenciada pelo grupo minoritário, aspecto lembrado por outras definições". 37,38

Nos próximos parágrafos, tentar-se-á demonstrar que a noção de ambiência revelase especialmente pertinente para se pensar nos direitos dos idosos, com base em dois argumentos. Primeiramente, diversos exemplos ilustram que as ambiências urbanas são, por um lado, parcialmente forjadas pelo exercício efetivo dos direitos dos idosos, e em parte determinantes para o exercício destes direitos. Em segundo lugar, de um ponto de vista jurídico gerontológico, pensar-se em ambiências urbanas (no plural) permite não apenas dar conta da heterogeneidade da velhice, como também vislumbrar-se mais uma dimensão da noção de ambiência, vista também como espaço para um envelhecimento em dignidade, ${ }^{39}$ para o exercício e a efetivação de direitos, no caso, dos idosos.

\section{As correlaç̧ões entre o exercício de direitos dos idosos e as} ambiências urbanas: algumas ilustrações

Em 2012, a proporção da população residente em áreas urbanas no Brasil era de 84,8\%, tendo os idosos presença de $84,3 \%$ nessas áreas. ${ }^{40}$ Como promover o bem-estar dos cidadãos, ${ }^{* * * *}$ sem se pensar em ambiências urbanas? E com relação aos cidadãos idosos, como cogitar sua participação na vida comunitária ${ }^{* * * * *}$ ou o direito ao lazer e a diversões "que respeitem sua peculiar condição de idade" sem se levar em conta as questões de ambiência? Por outro lado, como será demonstrado mais adiante, como numa via de mão-dupla, o próprio exercício de direitos pelos idosos vai influenciar a configuração das ambiências, tornando-as mais diversas e inclusivas.

\footnotetext{
**** Artigo.182 da Constituição Federal de 1988 e Artigo $1^{\circ}$ do Estatuto da Cidade.

***** Estatuto do Idoso, Lei 10.741 de 2003: Artigo $2^{\circ}, \mathbb{\$} 1^{\circ}, \mathrm{V}$; Artigo 20.
}

Para citar alguns direitos nitidamente afetados pelas ambiências, sem pretender exaurir o tema, direito à saúde do idoso (Estatuto do Idoso, art. $3^{\circ}$ ) e o direito ao envelhecimento em dignidade serão prejudicados por fatores ambientais de insalubridade.? Também o pleno exercício do direito de participação na vida comunitária e do direito ao lazer e a diversões pelos idosos depende da existência de ambiências favoráveis. Não são apenas condições ou interações de ordem física, química e biológica que devem ser levadas em conta para isso. Respeitar a "peculiar condição de idade do idoso" implica um cuidado de ordem física, química e biológica, sem dúvida; é preciso pensar nas questões de acesso físico, nos perigos de exposição ao sol, no acesso à água potável, por exemplo; mas é igualmente preciso pensar nas peculiaridades socioculturais e econômicas da comunidade de idosos para a qual se programa determinada atividade de lazer, sob pena de comprometer-se o efetivo exercício do direito.

Um sentimento de insegurança, por exemplo, é relatado pelos idosos como um possível óbice para sair de casa (e, portanto, para o exercício de determinadas atividades de lazer e diversão) em realidades tão diversas como a cidade de Rennes, na França, ${ }^{41}$ e o bairro Brás, na cidade de São Paulo. ${ }^{22}$ Esse sentimento pode, contudo, ser provocado por motivos muito distintos nessas diversas realidades, e as razões também podem variar entre os diversos indivíduos de uma mesma localidade, pela influência de fatores como gênero, idade, educação ou condição socioeconômica. ${ }^{41}$ Assim, em Rennes, o sentimento de insegurança persiste, "embora seja seguidamente independente de fatos reais ou vividos", relacionando-se com o discreto policiamento, a iluminação considerada insuficiente, a multiplicidade de informações sobre delinquência e violência. Nesse sentido, "O medo de sair, principalmente à noite, pode constituir frequentemente um fator de isolamento". ${ }^{41} \mathrm{O}$ relatório indica que o sentimento de insegurança varia de acordo com a condição socioeconômica, tendendo a prevalecer sobre as classes mais favorecidas. 
Já no bairro do Brás, na cidade de São Paulo, uma das peculiaridades observadas nos discursos dos idosos foi um sentimento de insegurança relacionado à presença de migrantes

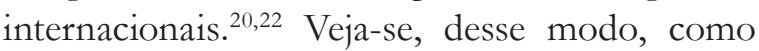
uma percepção subjetiva negativa do ambiente urbano por meio do viés da insegurança pode exercer influência sobre o exercício de direitos, como o de participação ou o direito ao lazer, dificultando ou impedindo as saídas das pessoas de suas casas.

No entanto, normas jurídicas e políticas públicas que implementem serviços ou medidas culturais e educativas que resultem em melhor percepção de segurança vão repercutir na própria configuração dos ambientes e das ambiências, com potencial maior ocupação dos espaços públicos por pessoas de idade mais avançada, e maior participação social, por exemplo, em atividades coletivas de lazer.

É necessário, contudo, precisar que, embora o Direito influa, como demonstrado, sobre a configuração das ambiências urbanas, essa influência é parcial e limitada, pois deixa boa margem de liberdade às iniciativas individuais e coletivas e não controla a incidência de outros elementos (como a chuva, por exemplo), nem as sensações e os sentimentos. Nem que se pretendesse determinar plenamente a configuração de determinada ambiência por meio de regras jurídicas, alcançar-se-ia o resultado almejado, visto que muitas coisas escapam do alcance da seara jurídica.

O Direito age sobre o meio ambiente, natural ou artificial, das cidades (preserva determinadas espécies de árvores, tomba determinado prédio), e exerce impacto igualmente sobre as atividades e o comportamento das pessoas (proíbe o comércio ambulante em determinadas ruas, interdita o uso de telefone celular em determinados locais). $\mathrm{O}$ Direito interfere até no que as pessoas vestem ou deixam de vestir (proibição da nudez ou do topless em determinados locais no Brasil, proibição da "dissimulação da face": questão do porte do véu integral, na França). Assim, não é apenas o Direito Urbanístico e o Direito Ambiental que influenciam as ambiências. $\mathrm{O}$ reconhecimento dos idosos enquanto grupo que, em razão de uma vulnerabilidade presumida, merece uma proteção jurídica específica, também é um fator transformador das ambiências urbanas.

No Brasil, a garantia do benefício de prestação continuada (BPC) para os idosos em situação econômica vulnerável poderá proporcionar que parte dos mesmos encontrem condições mínimas de subsistência, evitando-lhes, talvez, a situação de rua (Lei Orgânica de Assistência Social, art. $\left.2^{\circ}, \mathrm{I}\right){ }^{42}$

Uma observação importante consiste em não esquecer que os idosos, como qualquer cidadão, também são sujeitos de deveres. Como observam Puijalon \& Trincaz, ${ }^{43}$ no contexto francês, há uma curiosa tendência de afirmação da cidadania dos idosos pelo reconhecimento de direitos, mesmo que por meio de textos não vinculantes, como a Charte des droits et libertés de la personne âgée dépendante, enquanto que, para os jovens, a tendência é invertida, dando-se ênfase aos deveres.

No Brasil, as ambiências urbanas muitas vezes dificultam o exercício de deveres por parte dos idosos. Um exemplo dessa influência é a que incide sobre o exercício de voto, obrigatório até os 70 anos (Constituição Federal, art.14, $\$ 1^{\circ}$, inciso II, alínea "b”). ${ }^{1}$ Muitos locais de votação não oferecem acessibilidade adequada para pessoas com mobilidade reduzida. Presumindo as dificuldades que podem derivar dessa situação para as pessoas de mais idade, um projeto de emenda constitucional torna facultativo o voto para maiores de 60 anos, "portadores de doenças incapacitantes ou deficiência física" e aposentados (PEC no 409/05).

Sem que se pretenda entrar no mérito dos benefícios e desvantagens da obrigatoriedade do voto, o que escapa do escopo deste artigo, a evidência é que, num país em que o voto é obrigatório e onde a esperança de vida aumenta, pensar-se em baixar o marco etário para desobrigar os mais velhos deste dever reforça ainda mais a exclusão e alguns mitos negativos da velhice. Em se mantendo a obrigatoriedade 
de voto, a estratégia privilegiada deveria ser a melhoria das infraestruturas para o exercício desse direito/dever, e não a diminuição da idade para a isenção dessa obrigação.

Os exemplos citados ilustram as correlações entre as ambiências urbanas e o exercício de direitos (e deveres) dos idosos; essas correlações não podem ser ignoradas pelos agentes públicos no governo das cidades.

\section{A heterogeneidade da velhice nas ambiências urbanas}

Os indivíduos não são iguais. O próprio Direito reconhece tais diferenças, fazendo a igualdade formal de todos perante a lei, conquista das revoluções burguesas do século XVIII, evoluir para um princípio de igualdade material, pouco a pouco reconhecido ao longo do século XX e neste início de século. Dar tratamento igual aos iguais, e desigual aos desiguais, com vistas à promoção da equidade, eis o que se pugna, grosso modo, por meio desta nova concepção. Além disso, nessa transição para o século XXI, um discurso e políticas de reconhecimento somamse ou sobrepõem-se, segundo alguns, às ideias e políticas de justiça distributiva.

Com efeito, como afirma Boaventura Santos ${ }^{44}$ : "as pessoas e os grupos sociais têm o direito a ser iguais quando a diferença os inferioriza, e o direito a ser diferentes quando a igualdade os descaracteriza". Em países como os Estados Unidos ou o Brasil, surgem, assim, as políticas de discriminação positiva, ou ações afirmativas. Minorias e grupos vulneráveis são reconhecidos com a específica afirmação de seus direitos. ${ }^{45}$ Em última análise, esse processo visa à reafirmação da Humanidade comum de grupos historicamente discriminados, para a garantia de sua plena participação na sociedade. Dentre estes reconhece-se, como lembrado por Bobbio, ${ }^{46}$ a categoria dos idosos.

No campo gerontológico, o reconhecimento das diferenças passa pela afirmação da heterogeneidade da velhice, ${ }^{47}$ pois os idosos não podem ser vistos como uma massa homogênea: cada indivíduo tem uma história, valores e atributos próprios. Aliás, como afirmam, Goldstein \& Siqueira, ${ }^{48}$ a heterogeneidade inclusive se acentua à medida que as pessoas envelhecem, com as distintas intercorrências que marcam os ciclos vitais individuais. Quanto aos aspectos biológicos, embora uma das características gerais da velhice seja o declínio de funções, tal processo não é universal para todos os domínios do organismo e "ocorre em diferentes ritmos para as pessoas e grupos". ${ }^{49}$

As ambiências urbanas devem refletir toda essa heterogeneidade e diversidade, permitindo e criando espaços de manifestação e participação para que os idosos possam exercer sua cidadania. Devem inclusive refletir a diversidade cultural, também reconhecida pela Carta Constitucional brasileira $^{1}$ como um direito fundamental de terceira geração (artigos 215 e 216). E na medida em que a noção de "ambiência" integra uma dimensão subjetiva, a partir do que é experimentado, vivenciado, pelos indivíduos, ela pode ser particularmente interessante para dar conta da heterogeneidade dos grupos, e no que interessa à reflexão aqui empreendida, dos idosos. Se integrada nas políticas públicas urbanas, em especial aquelas voltadas ao idoso, a noção de ambiências urbanas pode (ou deveria) suscitar um interesse maior pelo olhar do cidadão, com a implementação de estratégias participativas.

Construir ambiências urbanas inclusivas certamente nãoé uma meta simples, ainda mais em se tratando de regiões metropolitanas brasileiras, nas quais grandes contingentes de pessoas vivem em ocupações precárias, desordenadas, sem as mínimas condições necessárias para um envelhecimento em dignidade. Para as pessoas que não têm água potável ou esgotamento sanitário em suas residências, ou que vivem sob a ameaça de uma expulsão, uma preocupação com calçadas ou bancos, demandas recorrentes das pesquisas "Cidade Amiga do Idoso", ${ }^{14}$ talvez possa parecer menos relevante. Por outro lado, para o problema de isolamento em que vivem idosos de classe média ou alta, a oferta de espaços de convívio social ou de serviços em domicílio 
pode configurar uma necessidade primordial. Seja lembrada, como ilustração, a tragédia que acometeu milhares de idosos na França, com a onda de calor de 2002. ${ }^{50}$ Tais exemplos demonstram a necessidade de se incorporar a heterogeneidade da velhice nas políticas públicas urbanas, a partir das necessidades e vivências expressas pelo cidadão participativo.

Por isso, para conhecer as ambiências, é tão importante ouvir o cidadão e, no que interessa neste trabalho, o idoso. A título de exemplo, entrevistando idosos sobre o atendimento no Hospital de Clínicas de Porto Alegre, o trabalho de Gonçalves $^{28}$ - revela que podem existir diferentes percepções sobre a ambiência dependendo do estado de saúde e setor onde se encontra a pessoa. O trabalho aponta, entre diversos dados relacionados ao funcionamento do hospital, que melhorias têm sido feitas quanto à ambiência. Mas os idosos classificados como graves fizeram melhor avaliação da ambiência do que aqueles classificados como alto risco e risco intermediário. As críticas relacionadas à ambiência de determinado setor, segundo relatos, se referem à falta de higiene, de privacidade e de acomodação adequada.

Ouvir o cidadão idoso passa, portanto, a ser uma importante ferramenta para a apreensão e a eventual reconfiguração de ambiências nos espaços urbanos que reflitam a heterogeneidade da velhice, ambiências essas que irão influenciar o exercício de direitos, sendo ao mesmo tempo influenciadas por esse exercício.

\section{CONSIDERAÇÕES FINAIS}

Muitos e diversos são os desafios territoriais em face do envelhecimento populacional, passando das dificuldades relacionadas à mobilidade, ao uso das novas tecnologias, sem olvidar a promoção do convívio intergeracional, o que é ilustrado no trabalho sobre os desafios para uma maior e melhor concepção e coordenação de projetos para uso de novas tecnologias pelas pessoas mais velhas, no exemplo da cidade de Brest, na França. ${ }^{51}$ Como ensina Serres, ${ }^{52,53}$ se o Homem não é mais o mesmo "bicho", pois o "bicho urbano" que o Homem se tornou não é mais o mesmo "bicho rural", que outrora ele era, também o Homem que, em média, ultrapassa os 70 anos de expectativa de vida, como no caso brasileiro, não é o mesmo daquele do início do século $\mathrm{XX}$, que vivia, em média, a metade desse tempo.

O Direito deve estar a serviço das adaptações necessárias à organização das sociedades nesse novo contexto, tendo como norte a promoção dos direitos humanos para uma convivência harmoniosa de todas as gerações, de todas as culturas, e do Homem com as outras espécies e com o meio ambiente, lembrando sempre que o "local" e o "global" são intimamente relacionados.

Para o enfrentamento dos novos desafios relacionados a sociedades envelhecidas e urbanizadas, a noção de ambiência(s) urbana(s), que integra a percepção e a vivência do sujeito sobre o ambiente experimentado, pode servir como fundamento teórico para políticas e estratégias que deem voz ao cidadão, como as iniciativas de cidades e espaços amigáveis de todas as idades. Por um lado, as ambiências urbanas influem sobre o exercício de direitos, e por outro, sua configuração é também influenciada por esse exercício. Justamente pelo fato de centrar-se no ser em sua relação com o espaço, se essa noção for considerada no âmbito das políticas públicas, a mesma pode conduzir a uma maior representação das necessidades e da heterogeneidade da velhice nos ambientes urbanos.

Pelas fontes pesquisadas neste estudo, embora o emprego da noção de ambiências urbanas ainda pareça ser bastante tímido no contexto das leis, políticas públicas e estudos relacionados ao envelhecimento e à efetivação de direitos no Brasil, ela já aparece em algumas leis municipais e, distinguindo-se do conceito de meio ambiente tal como formulado na lei da política nacional do meio ambiente, revela-se pertinente para se pensar em cidades inclusivas não somente para todas as idades e distintas condições de mobilidade, mas igualmente para as diversas situações socioculturais. 


\section{REFERÊNCIAS}

1. Brasil. Constituição (1988). Constituição da República Federativa do Brasil. Brasília, DF: Senado Federal; 1988.

2. Ramos PR. A Velhice na Constituição. Sequência 1999;20(38):85-106.

3. Faleiros VP. Cidadania e direitos da pessoa idosa. Ser Social 2007;20:35-61.

4. Graeff B. Direitos do Consumidor Idoso no Brasil. Rev Dir Consum 2013;86:65-91.

5. Machado MA. O movimento dos idosos: um novo movimento social? Kairós 2007;10(1):221-33.

6. Brasil. Ministério do Planejamento, Orçamento e Gestão; Instituto Brasileiro de Geografia e Estatística. Sinopse do Censo Demográfico 2010. Rio de Janeiro: IBGE, 2011.

7. Closs VE, Schwanke CH. A evolução do índice de envelhecimento no Brasil, nas suas regiões e unidades federativas no período de 1970 a 2010. Rev Bras Geriatr Gerontol 2012;15(3):443-58.

8. Brasil. Lei no 8.842, de 4 de janeiro de 1994. Estabelece a Política Nacional do Idoso. Portal da Legislação: Leis Ordinárias. 2014. Disponível em: http://www.planalto.gov.br/ccivil_03/leis/18842.htm

9. Brasil. Lei no 10.741, de 1 outubro de 2003. Dispõe sobre o Estatuto do Idoso. Portal da Legislação: Leis Orginárias. 2014. Disponível em: http://www. planalto.gov.br/ccivil_03/leis/2003/L10.741.htm

10. Camarano A A. Estatuto do Idoso: avanços com contradições. Rio de Janeiro: IPEA; 2013.

11. Brasil. Lei no 10.257, de 10 de julho de 2001. Regulamenta os arts. 182 e 183 da Constituição Federal, estabelece diretrizes gerais da política urbana e dá outras providências. Portal da Legislação: Leis Orginárias. 2014. Disponível em: http://www.planalto.gov.br/ccivil_03/leis/ LEIS_2001/L10257.htm

12. Marrara T. Acessibilidade da infraestrutura urbana: conceito e análise evolutiva da legislação brasileira a partir da década de 1990. Rev Dir Públ Econ 2012;10:159-80.

13. Garon S, Beaulieu M, Veil A, Paris M, Bigonnesse C. L'expérience québécoise du programme 'Ville amie des aînés' de l'OMS: l'implantation dans sept projets pilotes. In: Viriot-Durandal JP, Pihet C, Chapon $\mathrm{PM}$,organizadores. Les défis territoriaux face au vieillissement. Paris: La documentation française; 2012.

14. Centeio H, Dias S, Rito S, Santinha G, Vicente H, Sousa L. Aveiro: cidade amiga das pessoas idosas!? Rev Bras Geriatr Gerontol 2010; 13(3):369-82.
15. World Health Organization. Active Ageing: a Policy Framework. Geneva: WHO; 2002.

16. Organização Mundial de Saúde. Guia global: cidade amiga do idoso. Genebra, Suíça:OMS; 2008.

17. Brasil. Decreto no 8.114, de 30 de setembro de 2013. Estabelece o compromisso nacional para o envelhecimento ativo e institui Comissão Interministerial para monitorar e avaliar ações em seu âmbito e promover a articulação de órgãos e entidades públicos envolvidos em sua implementação.Portal da Legislação: Leis Ordinárias. 2014. Disponível em: http://www.planalto.gov.br/ccivil_03/_Ato20112014/2013/Decreto/D8114.htm.

18. São Paulo (Estado). Decreto no 58.047, de 15 de maio de 2012. Institui o Programa Estadual "São Paulo Amigo do Idoso", e o "Selo Amigo do Idoso", e dá providências correlatas. 2014. Disponível em: http:// www.legislacao.sp.gov.br/legislacao/dg280202.nsf/5f b5269ed17b47ab83256cfb00501469/6c3017b4b70ec30 b83257a0000473ab0?OpenDocument

19. Brasil. Lei no 14.905 , de 6 de fevereiro de 2009. Cria o Programa de Envelhecimento Ativo, e dá outras providências. 2009. Disponível em: http://www. prefeitura.sp.gov.br/cidade/secretarias/direitos_ humanos/idosos/legislacao/index.php?p=11063

20. Bestetti ML, Graeff B, Domingues M. O impacto da urbanidade no envelhecimento humano: o que podemos aprender com a estratégia Cidade Amiga do Idoso? Kairós 2012;15(6):117-36.

21. Rauth J, Santos ER, Pedde V. Projeto RS Amigo do Idoso: uma amizade que não se efetivou. Porto Alegre: Textos Contextos 2012;11(1):156-71.

22. Graeff B, Bestetti ML, Domingues M. Bairro Amigo do Idoso no Brás: percepções sobre os migrantes internacionais. Kairós 2012;15(6):177-96.

23. Capelatto IR. O assédio moral, o assédio sexual e a síndrome de burnout na ambiência do trabalho. Rev Trib Reg Trab 15 a Reg 2010;37:23-7.

24. Carvalho AL, Prestes V. Plano diretor e proteção às ambiências urbanas como elemento do patrimônio cultural: a necessidade de aplicação do princípio da precaução no caso de Porto Alegre. Rev Magister Direito Imobil Reg Urb Amb 2005;1:9-26.

25. Thibaud JP. Le vécu des ambiances. L'ambiance, chemin faisant: vers une perspective internationale. Culture Recherche 2007 [acesso em 22 Jan. 2013];113:31-32. Disponível em: http://www. culturecommunication.gouv.fr/Etudes-etdocumentation/Publications/Tous-les-numeros-deCulture-et-recherche. 
26. Tixier N. L'usage des ambiances. Culture Recherches 2007 [acesso em 22 de janeiro de 2013];113:10-11. Disponível em: http://www.culturecommunication. gouv.fr/Etudes-et-documentation/Publications/ Tous-les-numeros-de-Culture-et-recherche.

27. Bestetti ML. Ambiência: o espaço construído como fator de envelhecimento saudável. In: PLURIS 2010: livro de resumo do $4^{\circ}$ Congresso Luso Brasileiro para o Planeamento Urbano, Regional, Integrado e Sustentável; 2010 Out 6-8; Faro: Universidade do Algarve.

28. Gonçalves AV. Avaliação do acolhimento no serviço de emergência do Hospital de Clínicas de Porto Alegre na perspectiva da pessoa idosa [dissertação]. Porto Alegre: Escola de Enfermagem da UFRGS; 2011.

29. Brasil. Ministério da Saúde, Secretaria de Atenção à Saúde, Política Nacional de Humanização. Formação e intervenção. Brasília, DF: Ministério da Saúde, 2010. (Cadernos HumanizaSUS ; v. 1) (Série B. Textos Básicos de Saúde)

30. Silva JA. Direito Urbanístico Brasileiro. São Paulo: Malheiros; 2006.

31. Mascaró L, Mascaró JJ. Ambiência urbana. 3a ed. Porto Alegre: Masquatro; 2009.

32. Rio de Janeiro (Município). Lei complementar no 111, de 1 o de fevereiro de 2011. Dispõe sobre a política urbana e ambiental do município, institui o plano diretor de desenvolvimento urbano sustentável do município do Rio de Janeiro e dá outras providências. 2014. Disponível em: http:// mail.camara.rj.gov.br/APL/Legislativos/contlei.nsf/ a99e317a9cfec383032568620071f5d2/cdd6a33fa14df5 24832578300076df48?OpenDocument.

33. Porto Alegre. Lei complementar no 434, de 1o de dezembro de 1999. Dispõe sobre o desenvolvimento urbano no município de Porto Alegre, institui o Plano Diretor de Desenvolvimento Urbano Ambiental Porto Alegre e dá outras providências. 2014. Disponível em: http://www.camarapoa.rs.gov.br/biblioteca/ Conselhos/LC434CompiladaatéLC638.pdf.

34. Porto Alegre. Lei complementar no 646, 22 de julho de 2010. Altera e inclui dispositivos, figuras e anexos na Lei Complementar $n^{\circ} 434$, de $1^{\circ}$ de dezembro de 1999 - Plano Diretor de Desenvolvimento Urbano Ambiental de Porto Alegre (PDDUA) -, e alterações posteriores, e dá outras providências. 2014. Disponível em: http://www2.portoalegre.rs.gov.br/ netahtml/sirel/atos/646\%20rep-PDDUA.
35. Brasil. Lei nº 6.938, de 31 de ago de 1981. Dispõe sobre a Política Nacional do Meio Ambiente, seus fins e mecanismos de formulação e aplicação, e dá outras providências. Portal da Legislação: Leis Ordinárias . 2014. Disponível em: http://www.planalto.gov.br/ ccivil_03/leis/16938.htm

36. Prieur M. Droit de l'environnement. 5e éd. Paris: Dalloz; 2004.

37. Lantero C. L'impact de la reconnaissance institutionnelle des minorités sur la discrimination. Rev Droit Public 2009;3:817-51

38. Graeff B. Minorias culturais: integração ou assimilação? : reflexões a partir do caso francês. In: Jubilut L, Bahia AG, Magalhães JL. Direito à Diferença. Vol. 1. São Paulo: Saraiva; 2013. p. 358.

39. Ancet P, Mazen NJ, Mourey, Pfitzenmeyer, organizadores. Vieillir dans la dignité: un combat pour demain. Bordeaux: Les études hospitalières; 2009.

40. Instituto Brasileiro de Geografia e Estatística. Síntese de Indicadores Sociais: uma análise das condições de vida da população brasileira. Rio de Janeiro: IBGE; 2013. (Estudos e Pesquisas, no 32), (Informação Demográfica e Socioeconômica).

41. Organization Mondiale de la Santé. Lyon, Ville Amie des Ainés. Geneve: OMS; [2010].

42. Brasil. Lei no 8.742, de 7 de dezembro de 1993. Dispõe sobre a organização da Assistência Social e dá outras providências. Portal da Legislação: Leis Ordinárias. 2014. http://www.planalto.gov.br/ccivil_03/leis/ L8742compilado.htm

43. Puijalon B, Trincaz J. Le droit de vieillir. Paris: Fayard; 2000.

44. Santos BS, Nunes JA. Introdução: para ampliar o cânone do reconhecimento, da diferença e da igualdade. In: Santos BS. Reconhecer para libertar: os caminhos do cosmopolitismo multicultural. Rio de Janeiro: Civilização Brasileira; 2003. p. 25-44.

45. Marques C, Miragem B. O Novo direito privado e a proteção dos vulneráveis. São Paulo: Revita dos Tibunais; 2012.

46. Bobbio N. A era dos direitos. Rio de Janeiro: Campus Elsevier; 2004.

47. Debert G. A construção e a reconstrução da velhice: família, classe social e etnicidade. In: Neri AL, Debert G, organizadores. Velhice e Sociedade. Campinas: Papirus;1999. p. 41-68. 
48. Goldstein L, Siqueira MEC. Heterogeneidade e diversidade nas experiências de velhice. In: Neri AL, Freire AS, organizadores. E por falar em boa velhice. Campinas: Papirus; 2000. p. 113-124.

49. Neri A, Yassuda M, organizadores. Velhice bemsucedida: aspectos afetivos e cognitivos. $3 \mathrm{a}$ ed. Campinas: Papirus; 2008.

50. Graeff B. Aquecimento global e proteção da pessoa idosa. In: Silva S, Cureau S, Leuzinger M, organizadores. Mudança do Clima: desafios jurídicos, econômicos e socioambientais. São Paulo: Fiúza; 2011.
51. Pennec S. Vieillesse et usages des TIC: analyse des réalisations et des logiques d'acteurs à l'échelle d'un territoire urbain. In: Viriot-Durandal JP, Pihet C, Chapon PM, organizadores. Les défis territoriaux face au vieillissement. Paris: Lá documentation Française; 2012. p. 137-155.

52. Serres M. "On a oublié d'inviter la Terre à la conférence sur le climat”. Le Monde. 21 dez. 2009: Planeté.

53. Serres M. Temps des crises. Paris: Le Pommier; 2009.

Recebido: 10/5/2013

Revisado: $14 / 1 / 2014$

Aprovado: 15/2/2014 